\title{
Stochastic Models for Simulating Parallel, Rotary, and Side-Opening Milking Parlors
}

\author{
R. Nitzan,* I. Bruckental, ${ }^{\star}$ Z. Bar Shira,† E. Maltz, ${ }^{\star}$ and I. Halachmi*1 \\ *Agriculture Research Organization (A.R.O.), The Volcani Center, P.O. Box 6, Bet Dagan 50250, Israel \\ †Hebrew University Jerusalem, P.O. Box 12, Rehovot 76100 Israel
}

\begin{abstract}
Simulation models of parallel, rotary, and side-opening milking parlors were built that could predict milking parlor performance according to herd size, number of milking stalls, labor quality, and cow characteristics. The models were validated by statistically comparing the duration of the simulated milking process with actual data collected at 3 dairy farms during $12 \mathrm{mo}$. Various scenarios were generated to study parlor performance, and the results indicated that for a parlor with up to 14 milking stalls, a side-opening design provided greater capacity than parallel or rotary parlors. Performance of a side-opening parlor was reduced by enlargement up to 20 milking stalls. For 10 to 40 milking stalls, a rotary design gave better performance than a double parallel design in terms of milking process duration and stall utilization. The presented models can serve as a practical tool in designing new parlors or changing operations of existing ones.
\end{abstract}

Key words: milking parlor simulation, design, operation, system engineering

\section{INTRODUCTION}

Building a milking parlor requires a large investment and represents a major contribution to operating costs (Thomas et al., 1997). Milking routine influences other management practices related to cow husbandry and labor allocation; therefore, it might affect farm profitability (Smith et al., 1997). Classical time-and-motion studies of the milking process have included its effect on parlor performance (Armstrong and Seltz, 1972; Thomas et al., 1996; Smith et al., 1998). Although a time and motion study is ideal for analyzing a simple system, it suffers from several limitations in relation to a complicated system such as a milking parlor. The complexity is caused by lack of data on the various parlor sizes and types and by confounding local effects

Received January 29, 2006

Accepted June 26, 2006.

${ }^{1}$ Corresponding author: halachmi@volcani.agri.gov.il such as labor quality and premilking treatments. Parlor performance is affected by local conditions such as milking management and herd physiology, as well as by the type and dimensions of the parlor (Wagner et al., 2001).

A simulation (i.e., a model that imitates the operations of a real-world process and system over time; Banks et al., 2001) is a suitable tool for studying complicated systems such as milking parlors (Bickert et al., 1972; Chang et al., 1994; Burks et al., 1998). A dynamic simulation model enables examination of the performance of a projected facility and of how best to adapt it to local conditions. Capability of simulations to encompass the stochastic nature of biological systems makes them suitable to handle the problems of designing and managing agricultural systems (Halachmi et al., 2002). Nevertheless, significant decisions concerning new or modified parlors are often made without the use of a simulation tool.

The objective of the present study was to develop a discrete-event-stochastic model for simulating and comparing milking parlor operations.

\section{MATERIALS AND METHODS}

\section{Model Design}

Three different milking parlors-parallel, rotary, and side-opening (also called tandem)—were modeled by using a process orientation approach (i.e., by studying the flow of cows through the parlor during a milking shift). Entities undergoing the process are the individual cows and the resources are the individual milking stalls. One milking shift is defined as the time between identification of the first cow entering the parlor per shift and the departure of the last cow. An entity (cow) enters a process module if a resource is unoccupied and is then held according to its individual milking time (IMT) and to the logic of the modeled system (parallel, rotary, or side-opening parlor).

\section{Process Description}

The milking process in each parlor was divided into sections (Table 1) and quantified in terms of probability distributions (PD, Table 2). In parallel and herringbone 
Table 1. Description of the stochastic components of the simulation model

\begin{tabular}{|c|c|}
\hline Process section & Description \\
\hline Milking process duration ${ }^{1}$ (MPD) & Time between the identification of the first cow and the departure of the last cow. \\
\hline Initial worker time ${ }^{2}$ (IWT) & $\begin{array}{l}\text { Time elapsed between the attachment of the milking claw to successive cows in the batch. } \\
\text { Includes premilking activities such as predipping and wiping, according to local milking routine. }\end{array}$ \\
\hline Individual milking time ${ }^{2}$ (IMT) & $\begin{array}{l}\text { Time elapsed from attachment of the claw until its automatic removal. Influenced by local pulsation } \\
\text { rate and vacuum and genetic traits regarding milking speed. }\end{array}$ \\
\hline Between batches $^{2}(\mathrm{BB})$ & $\begin{array}{l}\text { Time occupied by events between the release of a batch and the identification of the first cow of the } \\
\text { next batch. Includes exit of the former batch, cleaning of milking claw and parlor floor, and time } \\
\text { required for entry of next batch. }\end{array}$ \\
\hline Between $\operatorname{cows}^{2}(\mathrm{BC})$ & $\begin{array}{l}\text { Time occupied by events between the release of a cow and the identification of the next cow on a } \\
\text { single milking stall. Includes departure of former cow, cleaning of machines and parlor floor, and } \\
\text { time required for entry of next cow. }\end{array}$ \\
\hline Rotary parlor rotation time ${ }^{2}(\mathrm{RT})$ & Rotary cycle time. \\
\hline Stall utilization ${ }^{1}$ & Ratio between actual milking time and total stall operating time. \\
\hline
\end{tabular}

${ }^{1}$ Model outputs (simulation responses).

${ }^{2}$ Model inputs.

parlors, unoccupied milking stalls (resources) are occupied by a batch of cows. Initial worker time (IWT) is defined as the time elapsed between attachment of the milking claw to the udder of successive cows in the batch. Each cow waits for a milker to approach and attach the claw to her udder, after which her time is processed according to her IMT. The whole batch is held until the last IMT had ended and the milker has approached the slowest cow and administered the postmilking treatment, the duration of which is designated as completion worker time (CWT). The next simulation step represents the time between batches (BB), which encompasses the cleaning of the machines and the parlor floor and entry of the next batch of cows. Figures $1 \mathrm{a}$ and $1 \mathrm{~b}$, respectively, depict the process for the individual cow and for a batch of cows in a parallel parlor. The integrated process represented in the model includes the processing both of the individual cow and of the batch.

In a rotary parlor simulation, when an IMT per cow is less than the rotation time (RT), a milking stall (resource) is occupied by a cow for a period equal to $1 \mathrm{RT}$
(Figure 2a), whereas when IMT is greater than the RT (i.e., a cow takes more than one rotation cycle to complete her milking), then the resource is held by the same cow beyond the end of her IMT and until the end of the current rotary cycle (Figure $2 b$ ).

In a side-opening parlor each cow is an independent unit and each milking stall is an independent resource. The process duration is the sum of the time between successive cows (BC), the IMT, and the CWT. Figure 3 represents the process in a single side-opening milking stall.

\section{Model Implementation}

The model used the Arena 7.01 simulation software (Rockwell Automation, Milwaukee, WI; http:// www.rockwellautomation.com). At the beginning of each replication the model read the input variables from an external Excel file that was also accessible to the end user. The input parameters included herd size, number of milking stalls, number of milkers, worker skill levels, cycle time, and stochastic variables (IMT,

Table 2. Actual milking distributions observed on Gvulot (parallel parlor), Mevo-Choron (rotary parlor), and Dorot (side-opening parlor) farms

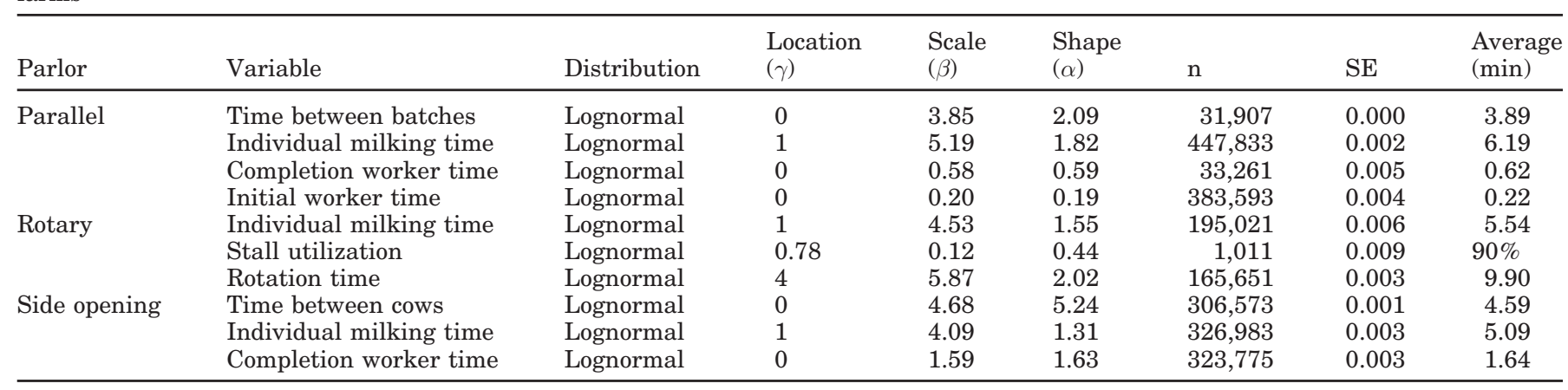


A.

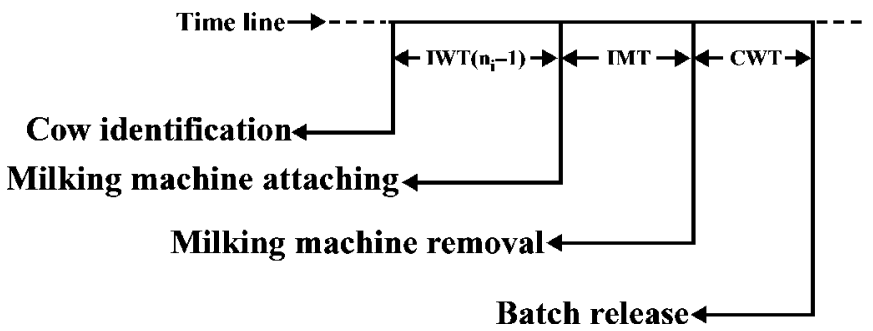

B.

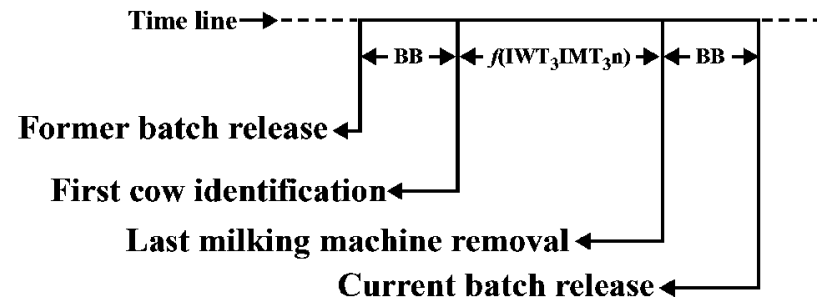

Figure 1. A parallel milking parlor. Milking process sections for (a) individual cow, and (b) batch. $\mathrm{n}=$ number of cows in a batch; $\mathrm{n}_{\mathrm{i}}=$ serial number of cow $\mathrm{i}$ in the batch; $\mathrm{BB}=$ between batches; CWT = completion worker time; IMT = individual milking time; IWT = initial worker time.

$\mathrm{BB}, \mathrm{BC}$, IWT, and CWT). The model output was the milking process duration (MPD). The stochastic variables were entered into the model as distributions, ac-

A.

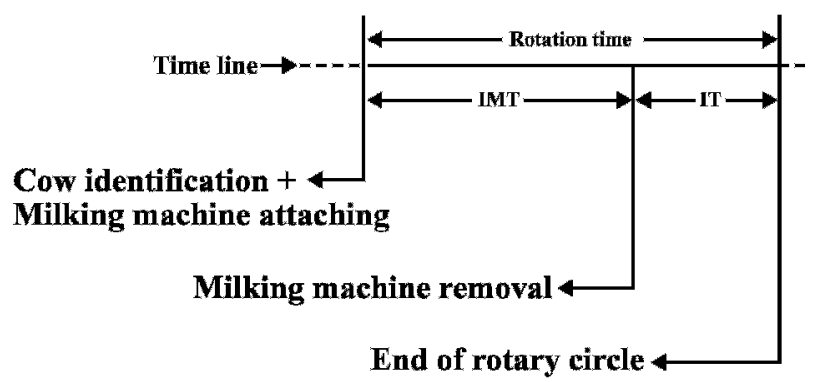

B.

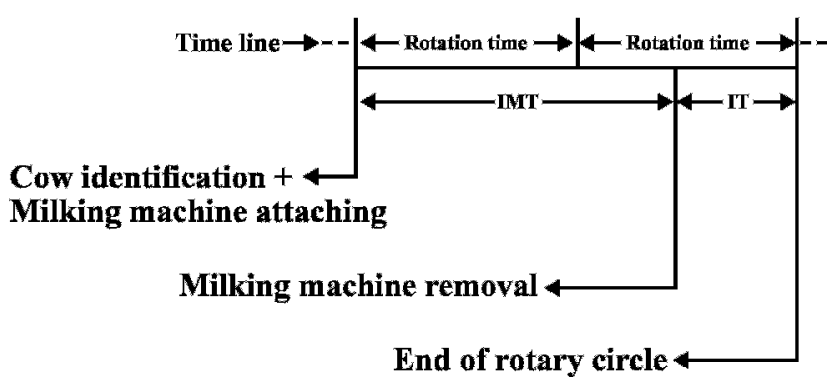

Figure 2. A rotary milking parlor. Milking process sections for the individual cow: (a) individual milking time < rotation time; (b) individual milking time $>$ rotation time. IT $=$ idle time; IMT $=$ individual milking time.

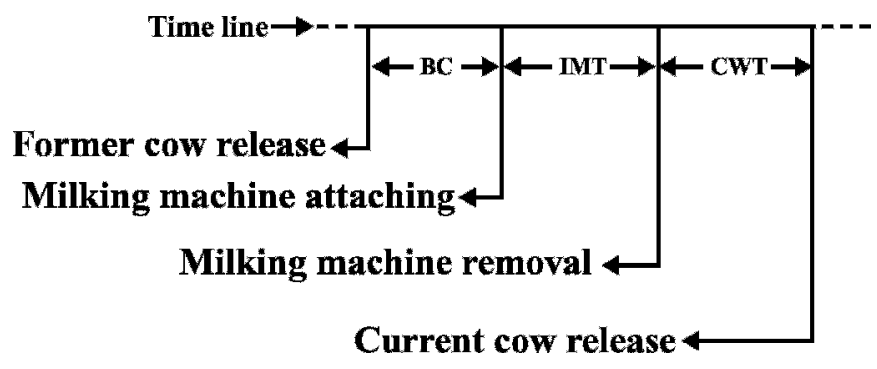

Figure 3. A side-opening milking parlor. Milking process sections for the individual cow. $\mathrm{BC}=$ between cows; $\mathrm{CWT}=$ completion worker time; IMT = individual milking time.

cording to which the model created a set of variables. Values (attributes) of each individual cow were attached to each entity. Based on the input data, the milking process was simulated; it included the cow's entry, milk flow, and the cow's exit from the milking stall. The MPD was exported to an external Excel (Microsoft Corp., Redmond, WA) output file. The values of the input data, as well as the distributions, were all adjustable, enabling the user to run a large number of replications, incorporating different sets of input parameters and process features characterized by PD. The flow chart is presented in Figure 4.

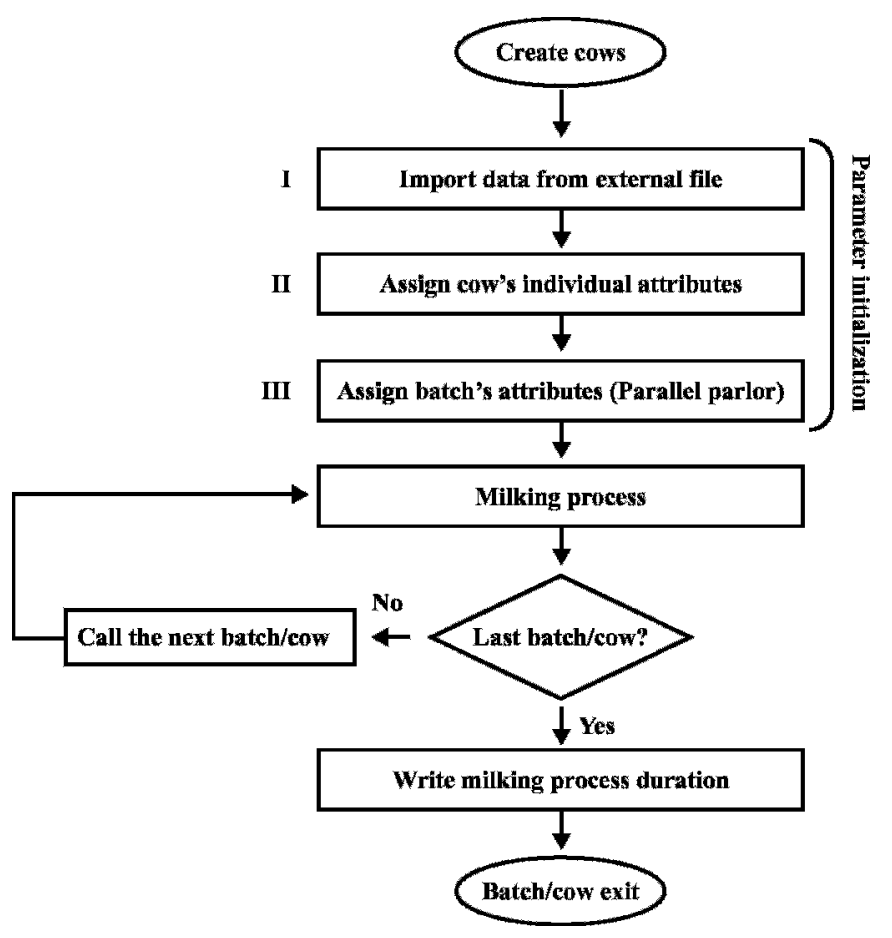

Figure 4. Schematic flow chart of a milking parlor simulation model. 


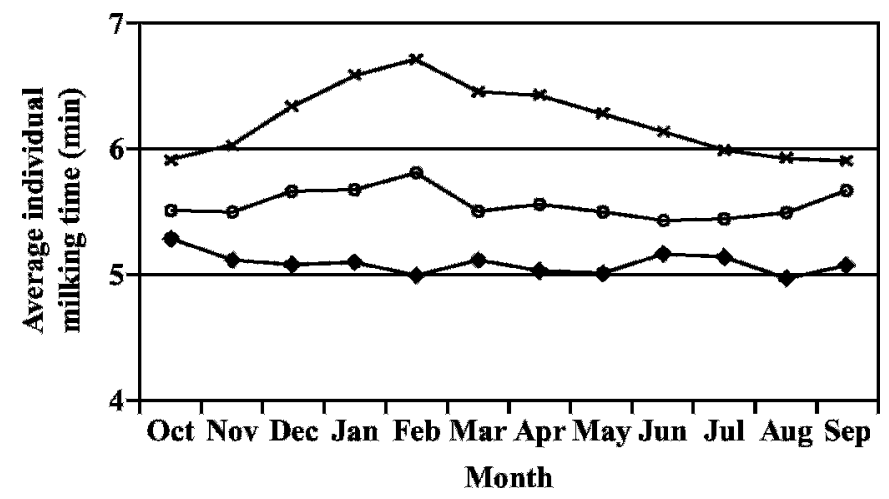

Figure 5. Average individual milking times in parallel $(x)$, rotary $(\bigcirc)$, and side opening $(\diamond)$ parlors.

\section{Data Collection and Analysis}

Data were automatically recorded on 3 dairy farms, Gvulot, Mevo-Choron, and Dorot, from September 2003 until January 2005. A double 14-stall parallel parlor was operated at the Gvulot farm, a 20 -stall rotary parlor at the Mevo-Choron farm, and a 20 -stall polygonal sideopening parlor at the Dorot farm. These herds comprised 480, 200, and 330 dairy cows, respectively, with minor changes during the year. All cows were milked thrice daily. All data files were manually screened to eliminate artifacts and errors. The IMT data were truncated to a range of 1 to $30 \mathrm{~min}$ for all herds. Other process-section data were not truncated because they represented the actual chain of events, including intermissions caused by group changeovers or by exceptional "on-off" interruptions to the milking process. Gaps in the data relating to a single shift were filled with the average values for the morning, afternoon, or evening shift, as appropriate, in the affected month. If data were missing from several separate shifts they were treated as missing values. Milking data were acquired with the AfiFarm management software (SAE Afikim, Kibbutz Afikim, Israel; www.afimilk.co.il). The PD of annual recorded data are presented in Table 2. The IMT for the 3 parlors are presented for comparison in Figure 5. February is the month having the greatest number of cows milked in both parallel and rotary parlors (Figure 5).

\section{Validation}

The simulated MPD were statistically compared with 3,000 actual MPD that were measured during the experiment (trace-driven validation, Banks 1998; correlated inspection approach, Law and Kelton, 1991). Input factors for each milking shift were herd size, average BB, IMT, IWT, CWT, BC, RT, and stall usage. The model was found to be statistically valid $(\alpha=0.05)$ according to Student's $t$-test and Kleijnen's test (Kleijnen et al., 1998, 2005). Validation results are presented in Table 3.

\section{RESULTS}

\section{Simulation Practice}

The various scenarios were simulated only after the model was validated. The PD and constants used are shown in Table 4.

\section{Milking Process Duration}

Simulated MPD are presented in Figure 6. For each model, the outputs of 100 replications are presented, each involving the milking of 500 cows in 20 milking stalls. Figure 6 shows how the shift durations vary because of the stochastic nature of the process. For instance, among 100 rotary parlor shifts, the difference between the longest and the shortest shift duration was $28.5 \mathrm{~min}(\mathrm{SD}=0.1)$. Variation among shift durations was larger for side-opening and parallel parlors, for which the differences between the longest and shortest shifts were $36.6(\mathrm{SD}=0.14)$ and $52.5(\mathrm{SD}=0.16)$ min, respectively.

Table 3. Validation of actual data vs. simulation average responses based on measured performance of milking-process durations for parallel, rotary, and side-opening parlors

\begin{tabular}{|c|c|c|c|c|c|c|c|}
\hline \multirow[b]{3}{*}{ Parlor } & \multirow[b]{3}{*}{$\mathrm{n}$} & \multicolumn{4}{|c|}{ Milking process duration } & \multicolumn{2}{|c|}{ Validation statistics } \\
\hline & & \multicolumn{2}{|c|}{ Real } & \multicolumn{2}{|c|}{ Simulated } & \multirow{2}{*}{$\frac{t \text {-test }^{1}}{P}$} & \multirow{2}{*}{$\frac{\text { Kleijnen }^{2}}{F \text { statistic }}$} \\
\hline & & Mean & SD & Mean & SD & & \\
\hline Parallel & 978 & 4.79 & 0.55 & 4.80 & 0.56 & 0.21 & 1.20 \\
\hline Rotary & 1011 & 1.89 & 0.22 & 1.89 & 0.23 & 0.40 & 2.65 \\
\hline Side opening & 1032 & 3.24 & 0.68 & 3.24 & 0.64 & 0.29 & 0.19 \\
\hline
\end{tabular}

${ }^{1} P$ critical $=1.96$.

${ }^{2} F$ critical $=3.00$. 
Table 4. Model inputs: Probability distributions and constant values chosen for the study farms ${ }^{1}$

\begin{tabular}{llllllrr}
\hline \multirow{2}{*}{ Parlor } & Variable & Distribution & $\begin{array}{l}\text { Location } \\
(\gamma)\end{array}$ & $\begin{array}{l}\text { Scale } \\
(\beta)\end{array}$ & $\begin{array}{l}\text { Shape } \\
(\alpha)\end{array}$ & $\mathrm{n}$ & $\mathrm{SE}$ \\
\hline Parallel & Time between batches & Lognormal & 0 & 4.60 & 2.02 & 880 & 0.002 \\
& Completion worker time & Lognormal & 0 & 0.62 & 0.53 & 928 & 0.024 \\
\multirow{2}{*}{ Rotary } & Initial worker time $^{*}$ Side opening & Weibull & 0 & 0.20 & 1.71 & 10,116 & 0.007 \\
& Stalls usage $^{2}(\%)$ & Constant & 89.6 & - & - & - & - \\
All & Rotation time $^{3}$ & Constant & 10 & - & - & - & - \\
& Time between cows $^{3}$ & Gamma & 0 & 2.86 & 2.45 & 3,780 & 0.006 \\
& Completion worker time & Lognormal & 0 & 1.67 & 1.53 & 4,039 & 0.001 \\
\hline
\end{tabular}

${ }^{1}$ Based on data from February morning shifts (greatest number of milking cows per month of the year).

${ }^{2}$ Actual proportion of empty stalls eliminates the need to input the individual milking time data.

${ }^{3} \mathrm{~A}$ decision variable.

\section{Parlor Simulated Capacity}

The MPD for milking 300 cows was $5.35 \pm 0.05,6.18$ \pm 0.15 , and $6.30 \pm 0.11 \mathrm{~h}$ in a side-opening, parallel, and rotary parlor, respectively, each having 10 stalls (Figure 7a). For the same 300 cows in a 20 -stall parlor, the MPD for a side-opening, parallel, and rotary parlor was $4.19 \pm 0.10,3.93 \pm 0.12$, and $3.29 \pm 0.08 \mathrm{~h}$, respectively (Figure 7b), and in a 30-stall parlor the corresponding MPD was $7.00 \pm 0.23,3.13 \pm 0.14$, and $2.30 \pm$ $0.06 \mathrm{~h}$, respectively (Figure 7c). Figure 8 illustrates the effects of the number of stalls on MPD, number of cows per hour, number of cows per stall per hour, and stall utilization. Under model assumptions, parallel and rotary parlors gave similar MPD for a 10-stall parlor; with a larger number of stalls, the rotary gave a shorter $(P<0.05)$ MPD than the parallel parlor, with the difference increasing as stalls were added. Decreasing MPD was accompanied by a corresponding rise in the number of cows per hour (CPH; Figure 8b). The relationship curves for parallel and rotary parlors exhibited positive, but diminishing marginal output increases as stalls were added. The marginal output increase was greater $(P<0.05)$ for a rotary than for a parallel parlor. Expanding a parlor from 18 to 20 milking stalls shortened $(P<0.05)$ the MPD by $9.5 \pm 0.22$ and $6.6 \pm 1.2 \%$ for rotary and parallel parlors, respectively. Adding 2 stalls to a 38 -stall parlor shortened $(P<0.05)$ MPD by $4.4 \pm$ 0.22 and $2.4 \pm 2.4 \%$ for rotary and parallel parlors, respectively; the 40-stall parlor enabled the milking of 110 and $178 \mathrm{CPH}$ with the parallel and the rotary design, respectively (Figure 8b). Expansion of the sideopening parlor elicited different trends. Expansion from 10 up to 20 stalls decreased $(P<0.05)$ MPD, with diminishing benefits from adding the 16th to 20th stalls; addition of further additional stalls resulted in a negative marginal output, with decreasing $\mathrm{CPH}$ and increasing MPD.

In 10-stall parlors, the side-opening design gave the largest $(P<0.05) \mathrm{CPH}: 56.6 \pm 0.9$ compared with 48.7

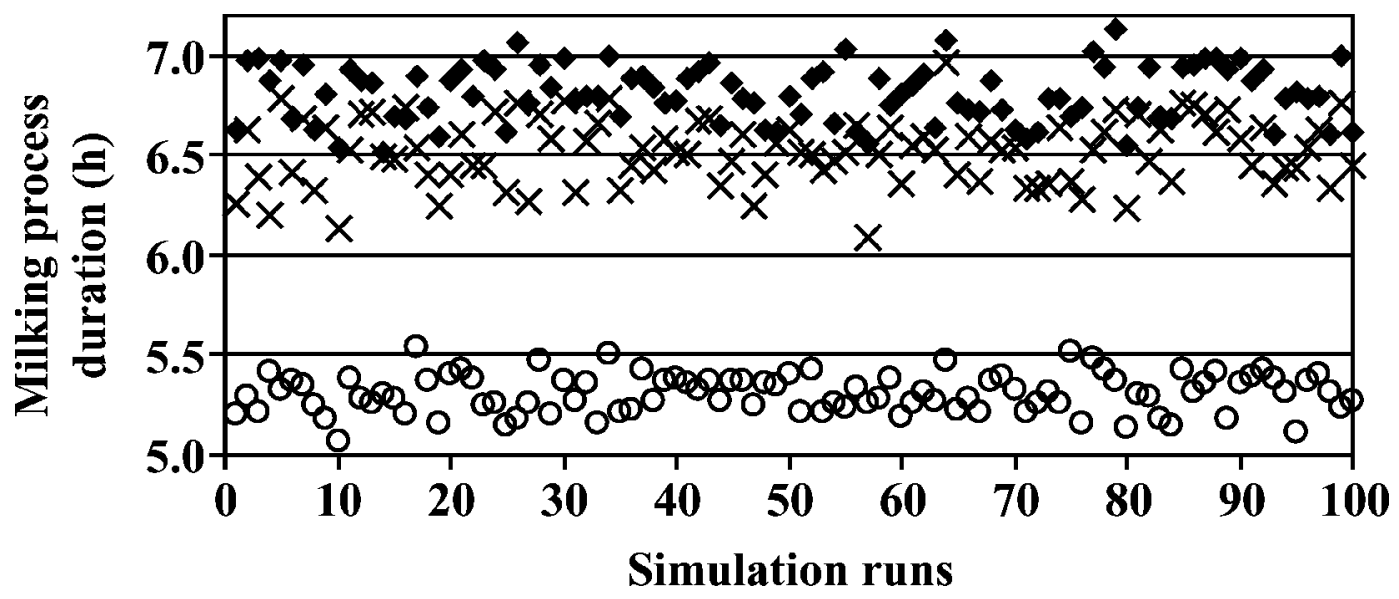

Figure 6. Magnitude of and variation in simulated milking process duration in parallel $(\times, \mathrm{SD}=0.16)$; rotary $(\bigcirc, \mathrm{SD}=0.10)$ and side opening $(\diamond, \mathrm{SD}=0.14)$ parlors. Herd size $=500$ cows; stalls number $=20 ; n=100$ replications. All other traits were identical for the 3 parlors. 


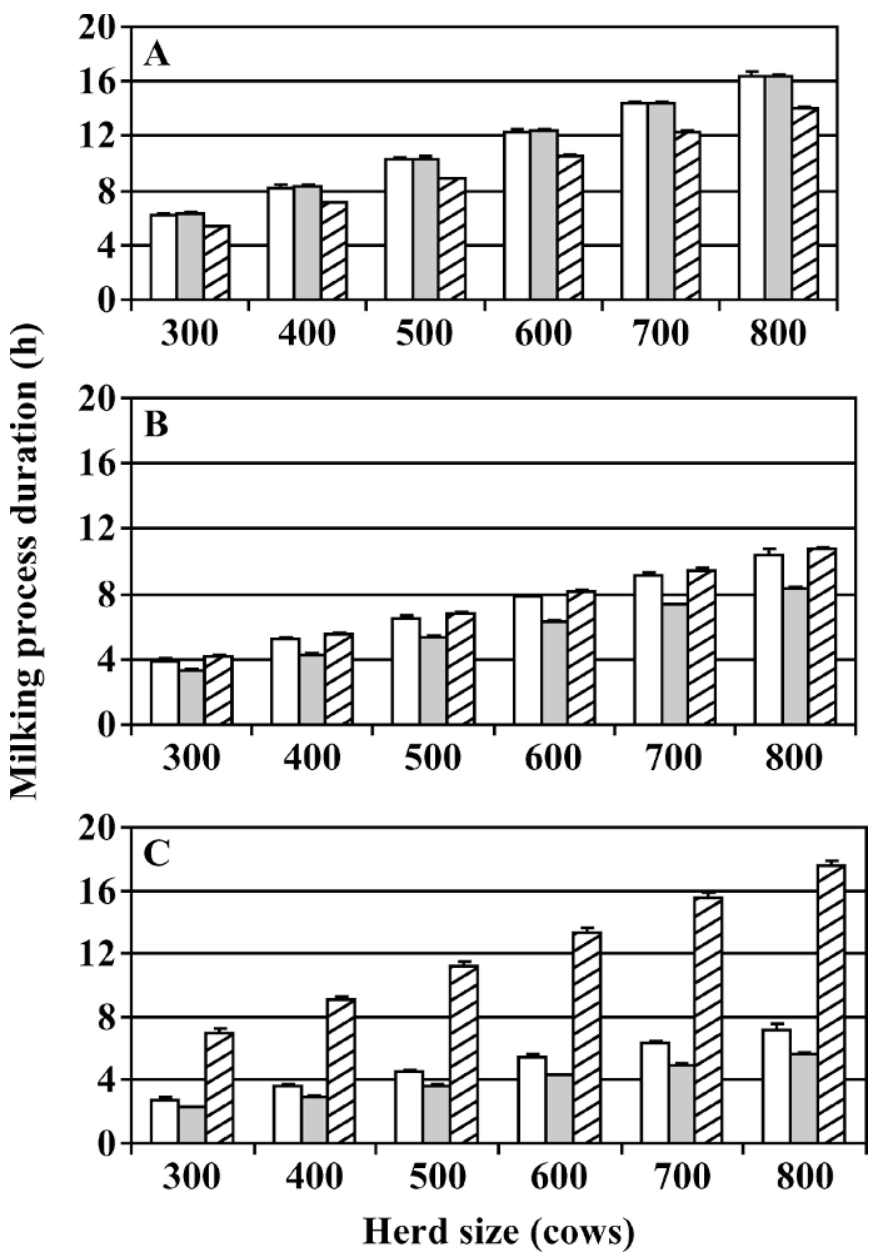

Figure 7. Milking process duration (hours \pm SD, $n=100$ replications) received from simulation models of parallel (open bars), rotary (rotation time of $10 \mathrm{~min}$; solid bars) and side opening (stippled bars) parlors including (a) 10, (b) 20, or (c) 30 milking stalls.

\pm 0.9 and $48.4 \pm 0.7 \mathrm{CPH}$ with the parallel and rotary designs, respectively (Figure 8c). With 20 and 30 milking stalls, the rotary parlor processed $94.3 \pm 1.7$ and $137.4 \pm 2.8 \mathrm{CPH}$, respectively, compared with $76.8 \pm$ 2.0 and $95.9 \pm 2.6$, respectively, in the parallel design, and $73.5 \pm 1.5$ and $44.6 \pm 1.2$, respectively, in the sideopening parlor. Parlor enlargement had differing effects on the numbers of cows per stall per hour (CSH). There was only a slight effect in the rotary design, which gave $4.8 \pm 0.07$ and $4.6 \pm 0.09 \mathrm{CSH}$ for 10 and 30 stalls, respectively (Figure $8 \mathrm{~d}$ ), whereas the same expansion resulted in a steep decrease from $5.7 \pm 0.09$ to $1.5 \pm 0.04 \mathrm{CSH}$ in a side-opening parlor, and a decline from $4.9 \pm 0.09$ to $3.2 \pm 0.09 \mathrm{CSH}$ in the parallel parlor.

Stall utilization is the ratio between actual milking time and total stall operating time. The model outputs showed large utilization of $68 \pm 0.01 \%$ for a small, 10 stall side-opening parlor. This decreased sharply with parlor enlargement; with over 16 stalls, the best exploited stalls were those of the rotary parlor (Figure 8d).

\section{Metamodel}

Simulation experiments are often analyzed by means of a linear regression model of their input and output data (Kleijnen and Deflandre, 2006). In the present study, 9,600 runs were selected for each parlor type according to the one-factor-at-a-time experimental design procedure described by Banks (1998). Equation 1 was fitted to the simulation outputs:

$$
\begin{gathered}
\mathrm{MPD}=\left(\mathrm{a}_{1} \times \mathrm{ST}\right)+\left(\mathrm{a}_{2} \times \mathrm{ST}^{2}\right)+\left(\mathrm{a}_{3} \times \mathrm{HS}\right) \\
+\left(\mathrm{a}_{4} \times \mathrm{HS} \times \mathrm{ST}\right)+\left(\mathrm{a}_{5} \times \mathrm{HS} \times \mathrm{ST}^{2}\right) \\
+\left(\mathrm{a}_{6} \times \mathrm{HS} \times \mathrm{ST}^{-0.59}\right)+\left[\mathrm{a}_{7} \times(\mathrm{HS} / \mathrm{ST})\right]+\mathrm{a}_{8}
\end{gathered}
$$

where MPD is in hours, ST is the number of stalls, and HS is herd size. The associated regression coefficients obtained for the parallel parlor were $\mathrm{a}_{6}=0.0777, \mathrm{a}_{8}=$ $0.0122\left(R^{2}=0.993\right)$. For the rotary parlor the coefficients were $\mathrm{a}_{7}=0.2009, \mathrm{a}_{8}=0.295\left(\mathrm{R}^{2}=0.999\right)$. For the sideopening parlor the coefficients were $\mathrm{a}_{3}=0.0344 ; \mathrm{a}_{4}=$ $-0.0023 ; \mathrm{a}_{5}=6.4036 \mathrm{e}-005 ; \mathrm{a}_{8}=0.301\left(\mathrm{R}^{2}=0.992\right)$.

Each parlor design has its own descriptive parameters. Equation 1 is useful for estimating parlor capacity without running the simulation software again. For instance, Table 5 shows that maximum daily usage of parallel, rotary, and side-opening parlors with 10 milking stalls enables 3 milkings per day of 401, 398, and 432 cows, respectively. With 30 stalls and 3 milkings per day, the parallel and rotary designs enable milking of 766 and 1,194 cows, respectively, whereas only 334 cows could be milked in a side-opening parlor of the same size. With 40 milking stalls, 3 milkings per day would enable milking of 1,593 cows in a rotary parlor, compared with 908 cows in the parallel design. These numbers are for comparison only because an 8$\mathrm{h}$ shift (3 milkings per day) allows no time for regular equipment maintenance and other cleaning.

\section{Milking Management Optimization}

Rotation Time on Rotary Parlor Performances. Effect of rotation time on the rotary parlor performances was examined for more than 100 milkings of 500-cow herds (i.e., $\mathrm{n}=100$ ). For parlors with 10,20 , 30 , and 40 milking stalls, reduction of the RT from 10 min (as used in the model) to 6 min reduced MPD by 8.0, 8.7, 9.5, and $10.2 \%$, (with SD of 1.8, 2.0, 2.1, and $2.8 \%$ ), respectively (Figure 9). Reductions in MPD achieved through $\mathrm{RT}$ reduction were comparable with 

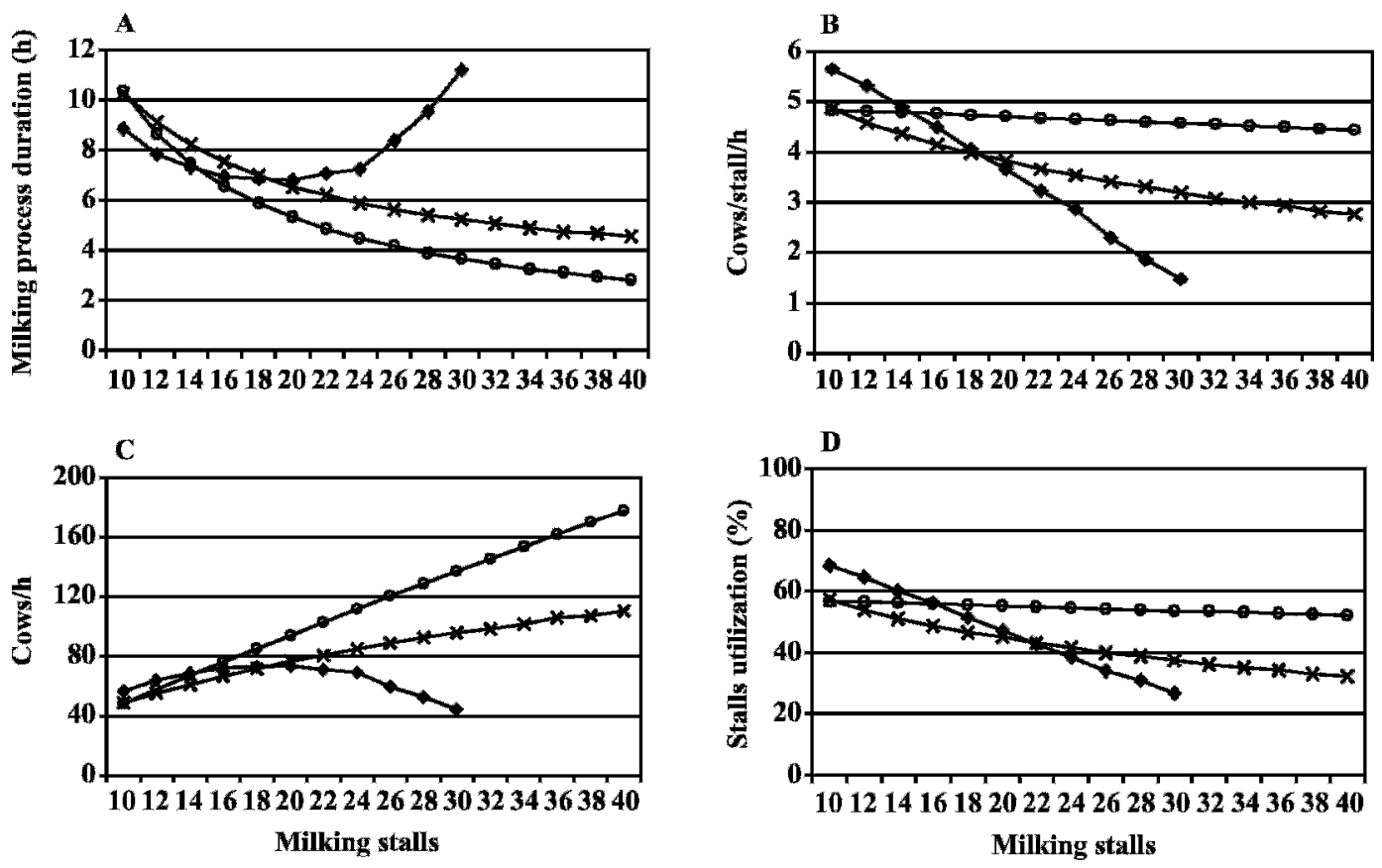

Figure 8. (a) Milking process duration, (b) cows per h, (c) cows per stall per h, and (d) stall utilization as functions of number of milking stalls in a parallel $(\times)$, rotary $(\bigcirc)$, or side opening $(\$)$ parlors. Herd size $=500$ cows, $\mathrm{n}=100$ replications.

the elevations in stall utilization (Figure 10), which were $37.4,54.4$, and $59.7 \%$ for $\mathrm{RT}$ of 16,10 , and $6 \mathrm{~min}$, respectively. For $\mathrm{n}=100$, SD was $0.9,1.9$, and $1.5 \%$, respectively. Proportions of cows requiring more than 1 rotation were $0.2,4.6$, and $42.2 \%$, respectively.

Batching Ten Percent of the Cows with the Longest Individual Milking Times. We used the parallel parlor model to examine the outcome of batching $10 \%$

Table 5. Model outputs: Numbers of cows that can be milked per session with $10,20,30$, or 40 milking stalls ${ }^{1}$

\begin{tabular}{lcclcr}
\hline & & \multicolumn{4}{c}{ Number of stalls } \\
\cline { 3 - 6 } & $\begin{array}{l}\text { DPU, }{ }^{2} \% \\
\left(\mathrm{MPD}^{3}{ }^{3} \mathrm{~h}\right)\end{array}$ & 10 & 20 & 30 & 40 \\
\hline Parallel & $40(3.2)$ & 160 & 241 & 306 & 363 \\
& $60(4.8)$ & 240 & 362 & 460 & 545 \\
& $80(6.4)$ & 320 & 482 & 613 & 726 \\
Rotary & $100(8)$ & 401 & 603 & 766 & 908 \\
& $40(3.2)$ & 159 & 318 & 478 & 637 \\
& $60(4.8)$ & 239 & 478 & 716 & 955 \\
Side opening & $80(6.4)$ & 318 & 637 & 955 & 1,274 \\
& $100(8)$ & 398 & 796 & 1,194 & 1,593 \\
& $40(3.2)$ & 163 & 207 & 126 & - \\
& $60(4.8)$ & 253 & 321 & 195 & - \\
& $80(6.4)$ & 343 & 435 & 265 & - \\
& $100 \mathrm{~S}(8)$ & 432 & 549 & 334 & - \\
\hline
\end{tabular}
$8 \mathrm{~h})$.

${ }^{1}$ Based on 3 milkings per day (1 milking session should not exceed

${ }^{2} \mathrm{DPU}=$ Daily parlor usage.

${ }^{3} \mathrm{MPD}=$ Milking process duration (duration of 1 shift in hours). of the cows with the longest individual milking times in each session. This strategy reduced MPD by an average of $6.8 \pm 3.3 \%$ for parlors with 10 to 40 stalls (Figure 11). The average absolute time-savings were $30.0 \pm 3.2$ and $14.7 \pm 1.8 \mathrm{~min}$ for parlors with 20 and 40 stalls, respectively. Milking sessions originally lasted $6.5 \pm 0.2$ and $4.5 \pm 0.2 \mathrm{~h}$, respectively, in these parlors.

Responses of Parlors to Decreases in Individual Milking Time. The 3 models were used to compare the responses of the parlors with decreases in IMT. The same conditions (number of cows, number of workers, practices, etc.) were simulated, but the original PD were altered by -1 to express a reduction by $1 \mathrm{~min}$ in the

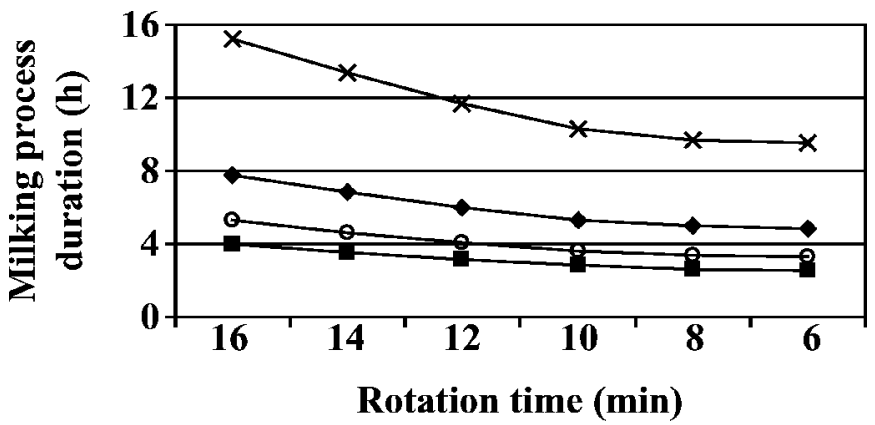

Figure 9. Effects of rotation time on the total milking process duration in a rotary parlor including $10(\times), 20(\diamond), 30(\bigcirc)$, or $40(\square)$ milking stalls. Herd size $=500$ cows, $n=100$ replications. 


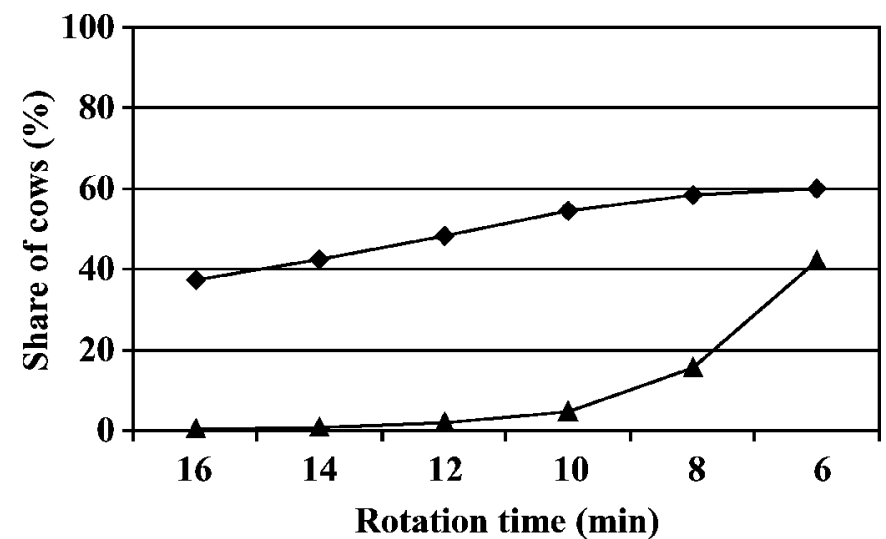

Figure 10. Effects of rotary parlor rotation time on the percentage of cows taking more than a single parlor rotation $(\boldsymbol{\Lambda})$ and on stall utilization $(\diamond)$.

IMT of each cow. In parallel, rotary, and side-opening parlors having 10 stalls, this modification shortened the MPD by $50.2 \pm 15.9,22.8 \pm 11.1$, and $50.0 \pm 10.5$ min, respectively. With 30 stalls, reductions were 15.9 $\pm 11.3,8.3 \pm 5.9$, and $18.2 \pm 23.8 \mathrm{~min}$, respectively. In terms of percentages of the original simulated MPD (Figure 12), the parallel parlor reductions were $8.1 \pm$ 2.5 and $4.9 \pm 4.7 \%$ for 10 and 40 stalls, respectively. In the side-opening parlor, MPD decreased from $9.4 \pm 1.9 \%$ to $2.6 \pm 3.5 \%$ as the parlor size increased from 10 to 30 stalls; in the rotary parlor, MPD was generally stable, ranging from 3.7 to $4.2 \%$.

\section{DISCUSSION}

Simulation is not a new concept (Sterk et al., 2006). As yet, most farms reported in the literature are being

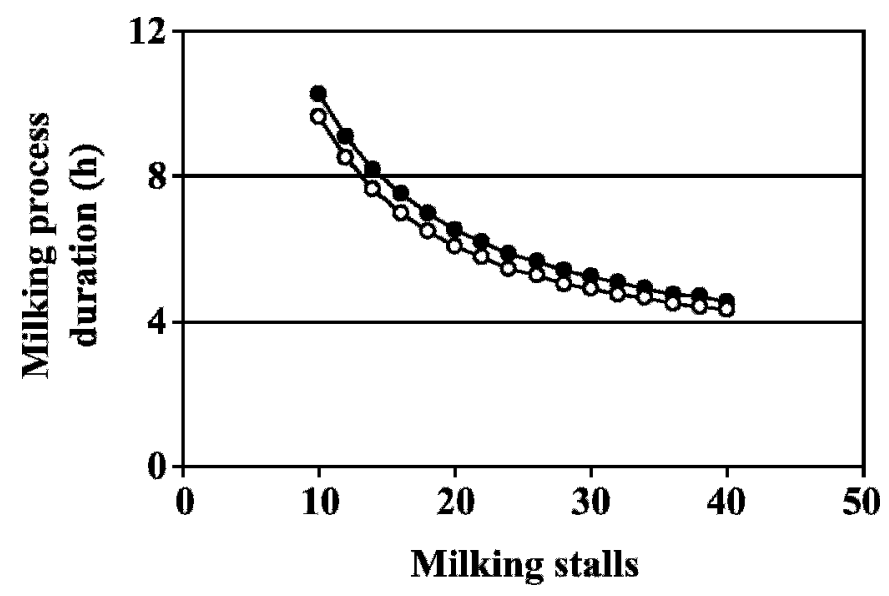

Figure 11. Milking process duration with random cow arrivals () or with grouping of the 50 cows having the longest milking times (O). Herd size $=500$ cows, $n=100$ replications.

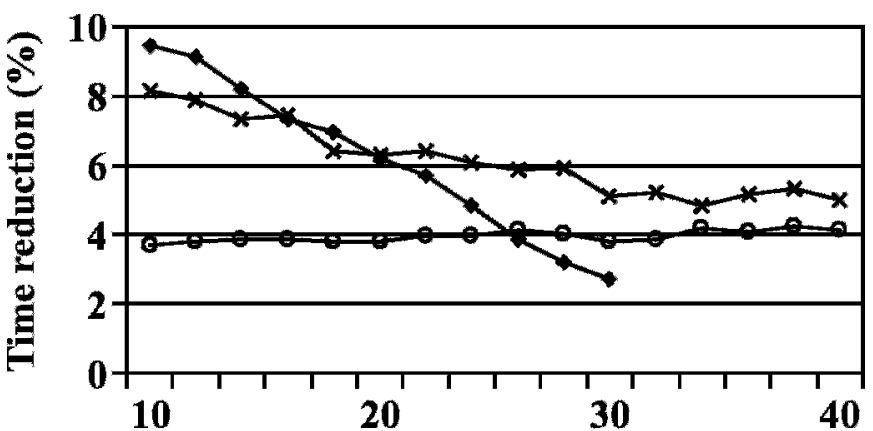

No. of milking stalls

Figure 12. Time reduction (\%) as a result of shortening individual milking time by 1 min in parallel $(\times)$, rotary $(O)$, and side-opening $(\checkmark)$ parlors. Herd size $=500$ cows, $n=100$ replications, parlor rotation time $=10 \mathrm{~min}$.

managed without simulation. Simulation provides a tool that may determine valid estimates of several factors including 1) number of cows per parlor type, 2) number of stalls in each parlor type, 3) number of milkings per day that is the maximum capacity under variety of practices, and 4) how to spread the cows in the milking groups with different milking frequencies; that is, 2,3 , 4 , or 5 milkings per day. Predicting exact numbers cannot be accurately calculated by rule-of-thumb, by drawing software, or by spreadsheet programs. Discrete-event-stochastic simulation, a more advanced tool, best handles this system and may provide further accurate predictions.

The stochastic nature of the milking process necessitates the use of simulation and PD rather than mean values, because a spreadsheet program that uses mean values might not reflect the variability of the real world. The ability of the simulation model to account for variability is an important advantage over classical timeand-motion studies. Figure 6 displays the results of 100 replications to illustrate the variation within an examined factor-in this case, milking duration. This results in a realistic forecast of the midpoint as well as extreme scenarios.

In the present study, the IMT for the 3 dairies were found to exhibit the same distribution (lognormal) and location $(\gamma=1)$, but they differed in the scale parameter $(\beta)$, with values of $5.19,4.53$, and 4.09 for parallel, rotary, and side-opening parlors, respectively. Thomas et al. (1996) fitted distributions with $\gamma=1$ and scale $(\beta)$ values of 6.04 and 5.78 for farms 1 and 2 , respectively. Halachmi (1999, 2000) found that the IMT was normally distributed with a mean value of $8.8 \mathrm{~min}(\mathrm{SD}=$ 2.2). The differences between the $\mathrm{PD}$ values found by Thomas et al. (1996) and those obtained in the present study can be attributed to differing herd characteristics 
such as milk yield and milk flow, and also to differing vacuum and pulsation rates. Halachmi $(1999,2000)$ measured the characteristics of robotically milked cows so that his times included several pre- and postmilking activities.

Comparisons between different parlors are meaningful only if all are run under similar scenarios. In the present study, the same IMT was used for all 3 parlors, and the chosen IMT data were those of the most heavily loaded scenario (i.e., the February morning shifts in Gvulot had the longest recorded monthly average IMT; Figure 5). Milking traits are also affected by the time of day, with the largest yields and longest IMT in morning milkings (Tančin et al., 2006). Rotation time is a decision variable that is set by the farm manager. In the present study, it was set to a large value (i.e., low rotary velocity of $10 \mathrm{~min}$ ). For other simulation goals, other RT values could be used. In parallel and side-opening parlors, installation of additional milking stalls leads to increased walking distances for the cows and the milkers. During the present study, 4 stalls were added to the side-opening parlor in the Dorot farm. This enabled us to assess the effects of such a modification by comparing 100 milking sessions from before the change with 100 sessions from after it. Extending the parlor from 16 to 20 milking stalls increased BC and CWT by 50 and $37 \%$, respectively. Additional survey work is needed to increase the accuracy of the model with respect to adjustable parameters such as parlor dimensions and layout, number of milkers, milking management, and so on.

The results indicate that the side-opening parlor offers an advantage over rotary or parallel parlors when the number of milking stalls is 14 or less. As the number of stalls increases, with a critical point at 20 stalls, efficiency of the side-opening design decreases dramatically, and for larger parlors the rotary design offers the best performance. This is mainly a result of the large distances between stalls and the serpentine route walked by the workers in the side-opening parlor. The present results were obtained under the assumption of constant number of milkers, whereas expansion of parallel and side-opening parlors requires additional labor. If we had simulated additional labor only for the enlarged parallel and side-opening parlors, then results might have been different, but because the parlors should be compared under identical conditions, we used the same labor force size in all the parlors. In simulation experiments, it is easy to eliminate the effect of the labor force. Values of IWT and CWT with unlimited staff theoretically could be greatly diminished or set at zero. This manipulation enhanced the apparent performance of the parlors, but did not change the previously determined trends and relationships. This is because of the proportion of the total time taken up by each part of the process. For the parallel parlor, the average $\mathrm{BB}$ and IMT were 3.89 and $6.19 \mathrm{~min}$, respectively (Figures $5 \mathrm{a}$ and $5 \mathrm{~b}$, respectively), compared with only 0.62 min for the average CWT (Figure 5c) and 0.22 min for the average IWT (Figure 5d). Likewise, for the sideopening parlor, the average BC and IMT were 4.59 and $5.09 \mathrm{~min}$, respectively (Figures $7 \mathrm{a}$ and $7 \mathrm{~b}$, respectively), compared with only 1.64 min for the average CWT (Figure 7c). These numbers confirm that reduction of CWT would have only a minor affect on MPD; therefore, the assumption that the parlors could be compared without adjusting the number of milkers was considered to be valid.

The rotary parlor, too, performed better than the sideopening parlor when the number of milking stalls exceeded 14. This finding is especially important in light of the fact that the RT of 10 min that was chosen for the present study represents a low speed, especially when dealing with small parlors. A shorter RT would have resulted in a wider gap in performance between the rotary and the other parlors.

Three cases were selected to demonstrate the usefulness of the models as a decision-making tool in achieving optimal management. In the first demonstration, the rotary simulation model was used to optimize rotation time. Accelerating the rotation shortened MPD, and the effect was stronger with small parlors (Figure 9). The velocity increase has a stronger effect on the smaller parlors, because in these parlors, larger numbers of rotations are required for a given herd size. In fact, more rapid rotation velocities increase the proportion of cows that occupy a stall for 2 or more rotations (Figure 10), but less time is wasted by cows that have been milked and are waiting for the rotation to end. In a rotary parlor, a shortening of the MPD is associated with rapid rotation, which enables a stall to be evacuated as soon as the individual milking has ended. With regard to shortening the MPD, the practical conclusion is that the optimal rotation velocity is the fastest that is consistent with high operating standards.

In the second demonstration, the strategy was to group the cows according to their IMT. In the presented scenario, batching the $10 \%$ of the cows with the longest IMT in a herd of 500 animals shortened MPD by an average of $6.8 \%(\mathrm{SD}=3.3 \%)$. When daily parlor usage is extremely high, this strategy can help to reduce the MPD without changing the staff or the facilities, but does require movement and regrouping of cows.

In the third demonstration, the model was used to examine the current tendency of selective breeding for a decreasing milk flow to decrease the duration of milking (Tančin et al., 2006). We examined and compared the responses of parlors to a 1-min decrease in IMT. The 
response of a side-opening parlor to this IMT decrease was strongly affected by the parlor size. The MPD in 10 - and 40-stall parlors was reduced by 9.4 and $2.7 \%$, respectively. The stronger response of a small parlor to IMT manipulation results from the independence of each cow as a separate unit. The shortening of each cow's IMT has a direct effect on the overall progress of the process. In a larger parlor, because of the increases in BC and CWT, the IMT makes a smaller contribution to the duration of the whole process; therefore, its alteration has a minor effect overall. This leads to the conclusion that the MPD in a large side-opening parlor can be shortened more effectively by addressing $\mathrm{BC}$ and CWT (for instance by increasing the number of milkers) rather than IMT.

In our particular case, we found no statistical evidence for rejecting the validity of our milking parlor simulation model (95\% confidence level), so it is useful for research and practical application. Perhaps other types and sizes of parlors can be addressed in the same manner such as robotic milking and aquaculture systems (Halachmi et al., 2001, 2005; Halachmi, 2004).

\section{CONCLUSIONS}

A stochastic simulation model was developed and statistically validated at the $95 \%$ confidence level. The model was used to compare the effects of various designs, herd sizes, and numbers of milking stalls on the performance of parallel, rotary, and side-opening milking parlors. Within the assumptions of the model, the results suggest that 1) side-opening parlors are superior to rotary and parallel parlors when containing fewer than 14 stalls; 2) throughput of a rotary parlor increases linearly with the number of milking stalls; 3) marginal output increase diminishes as stalls are added to a parallel parlor, but the diminution can be compensated for by increasing the labor force; 4) in a rotary parlor, reduction of the rotary cycle time increases stall utilization and therefore reduces the total milking time; 5) in a parallel parlor, grouping cows according to their IMT reduced the duration of the milking process; 6 ) batching the $10 \%$ of the herd with the longest IMT reduced the milking process duration by 5.4 to $7.6 \%$; and 7) in parallel and side-opening parlors, reducing IMT by $1 \mathrm{~min}$ elicited stronger responses in smaller than in larger parlors, whereas the response in rotary parlors was generally independent of parlor size. This scenario showed an overall reduction of up to $9.4 \%$ in MPD.

Once the model is validated, further scenarios can be run immediately. All relevant parameters are read by the model with no need for remodeling; therefore, a new farm can be modeled within a few minutes. This study implemented a technology of discrete-event-stochastic simulations. Three typical case studies were chosen to demonstrate the model capability and limitation. In further research or implementation, other parlors can be simulated as well. Further research is recommended for acquiring new time-and-motion probability distributions of different milking management regimes for other types of cows and parlor layouts to examine different scenarios and economic conditions.

\section{ACKNOWLEDGMENTS}

The authors thank reviewers of the Journal of Dairy Science for their help and critical comments that reshaped the manuscript into its final version.

\section{REFERENCES}

Armstrong, D. V., and C. O. Seltz. 1972. Milking parlor routine in double eight herringbone. J. Dairy Sci. 57:610-620.

Banks, J. 1998. Handbook of Simulation. John Wiley \& Sons Inc., New York, NY.

Banks, J., J. S. Carson, B. L. Nelson, and D. M. Nicol. 2001. DiscreteEvent System Simulation. Prentice Hall Inc., New York, NY.

Bickert, W. G., J. B. Gerrish, and J. H. Hutt. 1972. Simulated milking rates in various semi-automatic milking parlors. Trans. ASAE $15: 482-500$.

Burks, T. F., L. W. Turner, R. S. Gates, T. C. Bridges, and W. L. Crist. 1998. A stochastic simulation model for predicting cow throughputs in dairy parlors. Trans. ASAE 41:1789-1797.

Chang, W., D. H. Streeter, and L. R. Jones. 1994. An object-oriented model for simulating milking parlor operations. J. Dairy Sci. 77:84-93.

Halachmi, I. 1999. Design methodology for the robotic milking barn; modeling, simulation, validation, and optimization. $\mathrm{PhD}$ Thesis, Wageningen University, The Netherlands.

Halachmi, I. 2000. Designing the optimal robotic barn, Part 2: Behavior-based simulation. J. Agric. Eng. Res. 77:67-79.

Halachmi, I. 2004. Designing the automatic milking farm in a hot climate. J. Dairy Sci. 87:764-775.

Halachmi, I., A. Dzidic, J. H. M. Metz, L. Speelman, A. A. Dijkhuizen, and J. P. C. Kleijnen. 2001. Validation of simulation model for robotic milking barn design. Eur. J. Oper. Res. 134:677-688.

Halachmi, I., J. H. M. Metz, A. van't Land, S. Halachmi, and J. P. C. Kleijnen. 2002. Optimal facility allocation in a robotic milking barn. Trans. ASAE 45:1539-1546.

Halachmi, I., Y. Simon, R. Guetta, and E. M. Hallerman. 2005. A novel computer simulation model for design and management of recirculating aquaculture systems. Aquacult. Eng. 32:443-464.

Kleijnen, J. P. C. 2005. An overview of the design and analysis of simulation experiments for sensitivity analysis. Eur. J. Oper. Res. 164:287-300.

Kleijnen, J. P. C., B. Bettonvil, and W. van Groenendaal. 1998. Validation of trace-driven simulation models: A novel regression test. Manage. Sci. 44:812-819.

Kleijnen, J. P. C., and D. Deflandre. 2006. Validation of regression metamodels in simulation: Bootstrap approach. Eur. J. Oper. Res. 170:120-131.

Law, A. M., and W. D. Kelton. 1991. Simulation Modeling and Analysis. 2nd ed. McGraw-Hill, New York, NY.

Smith, J. F., D. V. Armstrong, M. J. Gamroth, and J. Harner, III. 1998. Factors affecting milking parlor efficiency and operator walking distance. Appl. Eng. Agric. 14:643-650. 
Smith, J. F., D. V. Armstrong, M. J. Gamroth, and J. G. Martin. 1997. Planning the milking center in expanding dairies. J. Dairy Sci. 80:1866-1871.

Sterk, B., M. K. van Ittersum, C. Leeuwis, W. A. H. Rossing, H. van Keulen, and G. W. J. van de Ven. 2006. Finding niches for wholefarm design models-contradictio in terminis? Agric. Syst. 87:211-228.

Tančin, V., B. Ipema, P. Hogewerf, and J. Mačuhová. 2006. Sources of variation in milk flow characteristics at udder and quarter level. J. Dairy Sci. 89:978-988.
Thomas, C. V., M. A. DeLorenzo, and D. R. Bray. 1996. A network simulation model of large herringbone and parallel milking parlors. J. Dairy Sci. 79:1960-1971.

Thomas, C. V., M. A. DeLorenzo, D. R. Bray, R. N. Weldon, R. A. Bucklin, and J. G. Martin, III. 1997. A stochastic economic analysis of large herringbone and parallel milking parlors. J. Dairy Sci. 80:2418-2428.

Wagner, A., R. W. Palmer, J. Bewley, and D. B. Jackson-Smith. 2001. Producer satisfaction, efficiency, and investment cost factors of different milking systems. J. Dairy Sci. 84:1890-1898. 